\title{
Febre maculosa brasileira
}

\section{Brazilian spotted fever}

\section{Resumo}

A febre maculosa brasileira (FMB) é uma doença infecciosa transmitida por carrapatos do gênero Amblyomma, tendo como principal agente etiológico a bactéria Rickettsia rickettsii, manifestando-se por um quadro febril agudo. O primeiro relato de riquetsiose no Brasil foi em 1900, no Instituto Bacteriológico de São Paulo, pelo Dr. Adolfo Lutz. A doença reemergiu e se tornou um importante problema de saúde pública no Brasil a partir da década de 1980. Desde então, observou-se aumento no número de casos, expansão das áreas de transmissão, transmissão em áreas urbanas e, em especial, elevadas taxas de letalidade. As rickettsias são bactérias intracelulares obrigatórias, com predisposição ao parasitismo de células endoteliais, que estão classicamente divididas em três grupos: o grupo tifo, composto por Rickettsia prowazekii e Rickettsia typhi; o grupo da febre maculosa, que inclui mais de 20 espécies válidas, principalmente associadas aos carrapatos (por exemplo, $R$. rickettsii e R. parkeri); e um grupo mais basal, em que estão incluídas $R$. bellii, R. monteiroi e R. canadensis. No Brasil, a transmissão da FMB está associada aos carrapatos do gênero Amblyomma, e as espécies de maior importância na transmissão da doença são A. sculptum (antigo A. cajennense) e A. aureolatum. A doença se caracteriza por febre, mialgia e cefaleia intensa, exantema, edema nas mãos e nos pés, sendo que em alguns casos apresenta-se de maneira generalizada. A doença causa sepse com comprometimento pulmonar, podendo ocasionar insuficiência respiratória aguda, problemas renais, como insuficiência renal aguda, diátese hemorrágica, lesões neurológicas com meningite, encefalite e icterícia. Os casos clínicos que evoluem para óbito, devido a diagnóstico e tratamento tardios, normalmente ocorrem entre o $5^{\circ}$ e o $15^{\circ}$ dias após o início dos sintomas. O diagnóstico da doença é feito com o emprego da reação de imunofluorescência indireta (RIFI), reação em cadeia da polimerase (PCR) e isolamento em cultivo celular. Após início das manifestações clínicas, o tratamento deve ser iniciado precocemente, interrompendo a administração após dois ou três dias do desaparecimento da febre. As medidas de vigilância e controle devem focar ações educativas e divulgar a doença para a população e os profissionais da saúde, repassando conhecimentos sobre sua existência, sobre medidas preventivas e sobre a importância do enviar carrapatos coletados nos pacientes ou encontrados no ambiente para identificá-los. 


\section{Abstract}

Brazilian spotted fever is an infectious disease transmitted by ticks of the genus Amblyomma, having as its main etiological agent the bacterium Rickettsia rickettsii, manifesting through acute febrile condition. The first report about rickettsial disease in Brazil was in 1900, at the Bacteriological Institute of São Paulo, by Dr. Adolfo Lutz. The disease has reemerged and became an important public health problem in Brazil since the 1980s. The number of cases has increased, as well as the expansion of transmission areas, transmission in urban areas, and, in particular, high lethality rates. Rickettsiae are obligate intracellular bacteria predisposed that act as parasites in endothelial cells, which are classically divided in three groups: the typhus group, composed of Rickettsia prowazekii and Rickettsia typhi; The spotted fever group, composed of more than 20 valid species, mainly associated with ticks (e.g., R. rickettsii and R. parkeri); and a more basal group that includes $R$. bellii, $R$. monteiroi and $R$. canadensis. The transmission of Brazilian spotted fever is associated mainly with the ticks Amblyomma sculptum (formerly $A$. cajennense) and Amblyomma aureolatum. The disease is characterized by fever, myalgia and severe headache, rash, edema in hands and feet, and in some cases shows general symptoms. The disease causes sepsis with pulmonary involvement, which can cause acute respiratory failure, renal problems, such as acute renal failure, haemorrhagic diathesis, neurological lesions with meningitis, encephalitis and jaundice. The cases of death by late diagnosis and treatment usually occur between 5 and 15 days after the onset of symptoms. Diagnosis of the disease is made through the indirect immunofluorescence reaction (IFI), polymerase chain reaction (PCR) and isolation in cell culture. Treatment should initiate at the beginning of clinical signs and stop only two or three days after fever disappearance. Surveillance and control measures must focus on educational actions for the population and health professionals, passing on knowledge about the existence of the disease, its preventive measures, and the importance of sending ticks collected in patients or found in the environment to health centers for identification.

\section{Palavras-chave}

Febre maculosa brasileira. Rickettsia rickettsii. Carrapatos. Amblyomma sculptum. Amblyomma aureolatum.

\section{Keywords}

Brazilian spotted fever. Rickettsia rickettsii. Ticks. Amblyomma sculptum. Amblyomma aureolatum.

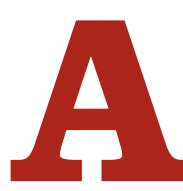

febre maculosa brasileira (FMB), doença infecciosa transmitida por carrapatos do gênero Amblyomma, cujo principal agente etiológico é a bactéria Rickettsia rickettsii, manifesta-se por um quadro febril agudo.

Os primeiros casos da doença foram registrados nos Estados Unidos no início do século XX, recebendo o nome de "febre maculosa das Montanhas Rochosas". Mais tarde, Howard Taylor Ricketts foi o primeiro a isolar a $R$. rickettsii, elucidando importantes aspectos epidemiológicos da enfermidade, que incluíram a participação de carrapatos em sua transmissão (no caso, o Dermacentor andersoni) e a dependência de hospedeiros silvestres para o ciclo de transmissão. 
O primeiro relato de riquetsiose no Brasil foi em 1900, no Instituto Bacteriológico de São Paulo, pelo Dr. Adolfo Lutz, sendo posteriormente descritos casos da infecção em humanos por José Toledo Piza - em 1932 - no município de São Paulo, na época, denominando a afecção de "tifo exantemático".

A doença reemergiu e se tornou importante problema de saúde pública no Brasil a partir da década de 1980. Desde então, observou-se aumento no número de casos, expansão das áreas de transmissão, principalmente em áreas urbanas e, em especial, elevadas taxas de letalidade. De 1985 a julho de 2011, foram confirmados 440 casos de FMB e 152 óbitos em 79 municípios no estado de São Paulo. Entre os anos de 1997 e 2010, notificaram-se no Brasil 868 casos confirmados da doença, com 227 óbitos, distribuídos entre São Paulo, Minas Gerais, Espírito Santo, Rio de Janeiro, Bahia, Paraná, Santa Catarina, Rio Grande do Sul e Distrito Federal (PINTER et al., 2011; PINTER et al., 2016).

No período de 2007 a 2015, foram notificados 1.322 casos suspeitos de FMB em residentes da região metropolitana da cidade de São Paulo (RMSP), com apenas 7\% de confirmações. A distribuição dos casos ocorridos na região demonstra uma relação com proximidade a resquícios de vegetação (Figura 1). A gravidade da doença ficou demonstrada tanto pela taxa de hospitalização, de 93\% (69 casos), quanto pela letalidade, de 64\%, com 47 óbitos (PINTER et al., 2016).

\section{Etiologia}

Rickettsias são bactérias intracelulares obrigatórias, com predisposição ao parasitismo de células endoteliais, que estão classicamente divididas em três grupos: o grupo tifo, composto por Rickettsia prowazekii e Rickettsia typhi, associadas com piolhos e pulgas, respectivamente; o grupo da febre maculosa, que inclui mais de 20 espécies válidas, principalmente associadas aos carrapatos (por exemplo, $R$. rickettsii e R. parkeri) e pelo menos uma espécie associada com pulgas, $R$. felis (PAROLA; PADDOCK; RAOULT, 2005); e um grupo mais basal, em que estão incluídas $R$. bellii, R. monteiroi e $R$. canadensis (MCKIEL; BELL; LACKMAN, 1967; LABRUNA et al., 2011; PACHECO et al., 2011).

No Brasil, a transmissão da FMB está associada aos carrapatos do gênero Amblyomma, e as espécies de maior importância na transmissão da doença são $A$. sculptum (antigo A. cajennense), A. aureolatum e A. ovale.

$\mathrm{O}$ primeiro (Figura 2) é encontrado nos biomas do Cerrado, Pantanal e em áreas degradadas da Mata Atlântica nos estados da região Sudeste e Centro-Oeste, na Bahia, no Paraná e em Santa Catarina,

apresentando baixa especificidade por hospedeiros, alimentando-se em equídeos, bovinos, caprinos, suínos, aves silvestres, cães, gatos, capivaras (Hydrochoerus hydrochaeris) e inclusive no homem.

A transmissão da Rickettsia sp para os seres humanos ocorre, principalmente, pela picada do carrapato infectado na fase ninfal, mas existem relatos de transmissão em outras fases do seu ciclo de vida. O A. sculptum é o responsável pela transmissão da FMB no interior do estado de São Paulo (Quadro 1).

$\mathrm{O}$ A. aureolatum (Figura 3) é encontrado nas regiões de São Paulo, Rio de Janeiro, Minas Gerais e no Sul do Brasil. É conhecido como "carrapato amarelo do cão", localizado preferencialmente na Floresta Pluvial Atlântica e é o responsável pela transmissão da doença nos municípios da RMSP, conforme Quadro 1.

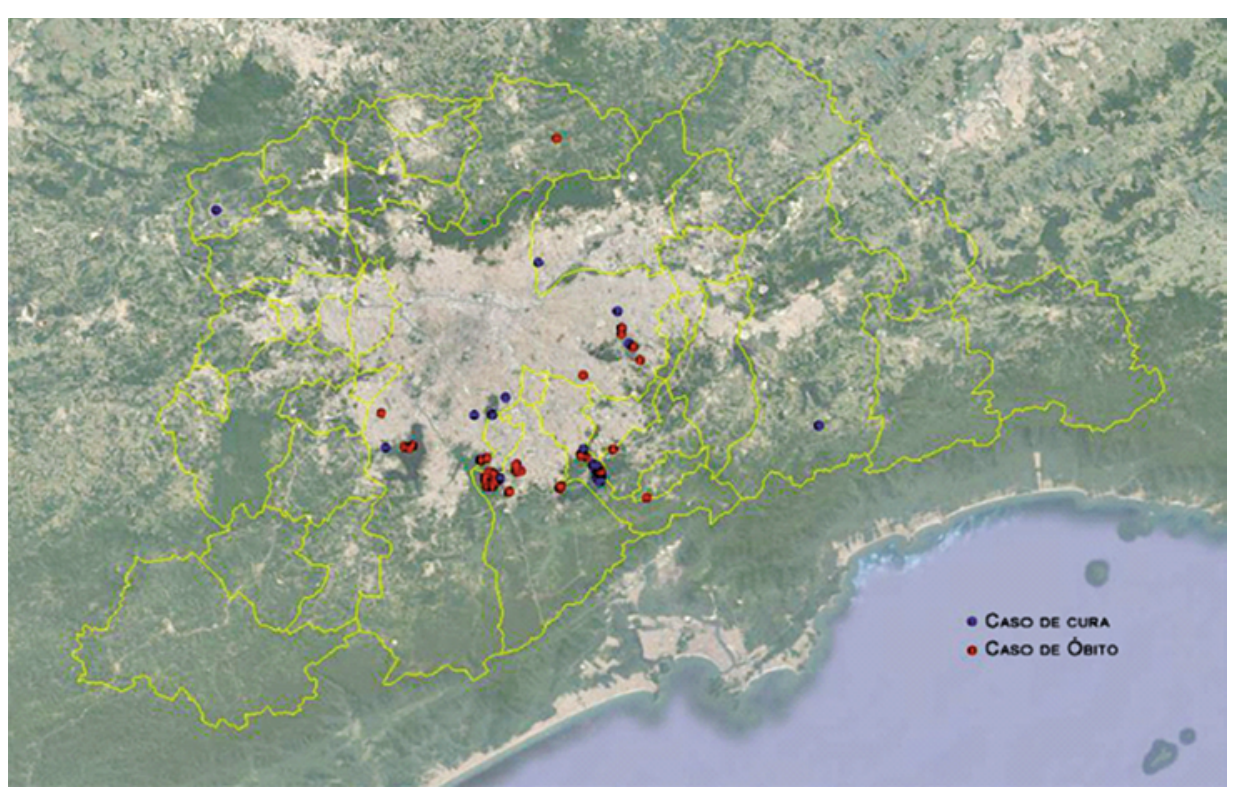

Figura 1 - Mapa da localização provável de infecção dos casos confirmados de FMB na região metropolitana de São Paulo, no período de 2007 a 2015. Fonte: PINTER et al., 2016. 


\begin{tabular}{|c|c|c|}
\hline CARACTERÍSTICAS ECOEPIDEMIOLÓGICAS & FMB DA RMSP & FMB DO INTERIOR DE SP \\
\hline Agente etiológico & Rickettsia rickettsii & Rickettsia rickettsii \\
\hline Taxa de letalidade & $56,12 \%$ & $53,44 \%$ \\
\hline Vetor & Amblyomma aureolatum & Amblyomma sculptum \\
\hline Taxa de infecção do carrapato em condições naturais & Baixa $(1-10 \%$ & Muito baixa $(\leq 1 \%)$ \\
\hline $\begin{array}{l}\text { Capacidade de infecção de transmissão transovariana e transestadial } \\
\text { da riquétsia }\end{array}$ & Alta $(100 \%)$ & Baixa $(<50 \%)$ \\
\hline Ocorrência de infestação no homem (hospedeiro acidental) & Rara (só por carrapatos adultos) & Muito comum (por larvas, ninfas e adultos) \\
\hline Tempo de fixação do vetor para efetiva transmissão & 10 minutos & Mínimo de 6 horas \\
\hline Hospedeiros do vetor & Passeriformes que frequentam o solo (para as larvas e ninfas) & $\begin{array}{l}\text { Cavalos, antas e capivaras (para todas as fases de } \\
\text { desenvolvimento do carrapato) }\end{array}$ \\
\hline Animal amplificador & Cães e canídeos silvestres (para os carrapatos adultos) & Capivara \\
\hline $\begin{array}{l}\text { Necessidade de um animal vertebrado amplificador para manutenção } \\
\text { da riquétsia na população de carrapatos }\end{array}$ & Ainda desconhecido & A curto prazo \\
\hline Áreas de transmissão & A médio e longo prazo & Cerrado e áreas degradadas \\
\hline Zona de transmissão & Mata atlântica de altitude & $\begin{array}{l}\text { [áreas de pastos sujos, matas ciliares, coleções } \\
\text { hídricas e presença de equinos e capivaras] }\end{array}$ \\
\hline Zona de transmissão & $\begin{array}{l}\text { [degradada, com residências adjacentes aos seus limites e } \\
\text { circulação de cães e gatos domésticos] }\end{array}$ & Rural (há tendência de urbanização) \\
\hline Sazonalidade & Urbana e periurbana & $\begin{array}{l}\text { Maior incidência de junho a setembro, com alguns } \\
\text { casos esporádicos durante o resto do ano }\end{array}$ \\
\hline
\end{tabular}

Quadro 1 - Características ecoepidemiológicas da FMB na região metropolitana e no interior do Estado de São Paulo. Fonte: (PINTER et al., 2016).

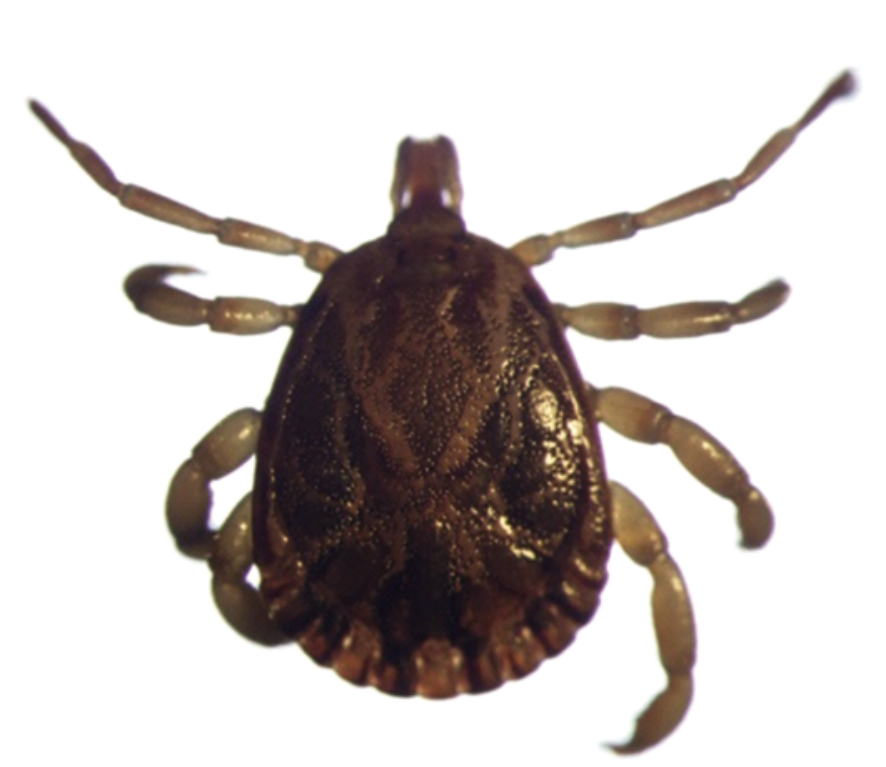

Figura 2 - Carrapato adulto macho da espécie A. sculptum. Fonte: Acervo do autor.

O crescimento desordenado da área urbana na periferia juntou áreas periurbanas com as matas remanescentes, expondo a população desses locais ao risco de ser parasitada por esses carrapatos.

Nas fases imaturas, o A. aureolatum possui como hospedeiros algumas espécies de aves passeriformes, e há também relatos em algumas espécies de roedores silvestres. Na fase adulta, parasita carnívoros, entre eles o cão doméstico. Nessa espécie, somente o estágio adulto pode parasitar seres humanos. Assim, a presença de cães e gatos com acesso a áreas de mata pode ser um fator de risco para a ocorrência de FMB em humanos, porque podem carrear carrapatos de seu ambiente natural para as residências (Figura 4).

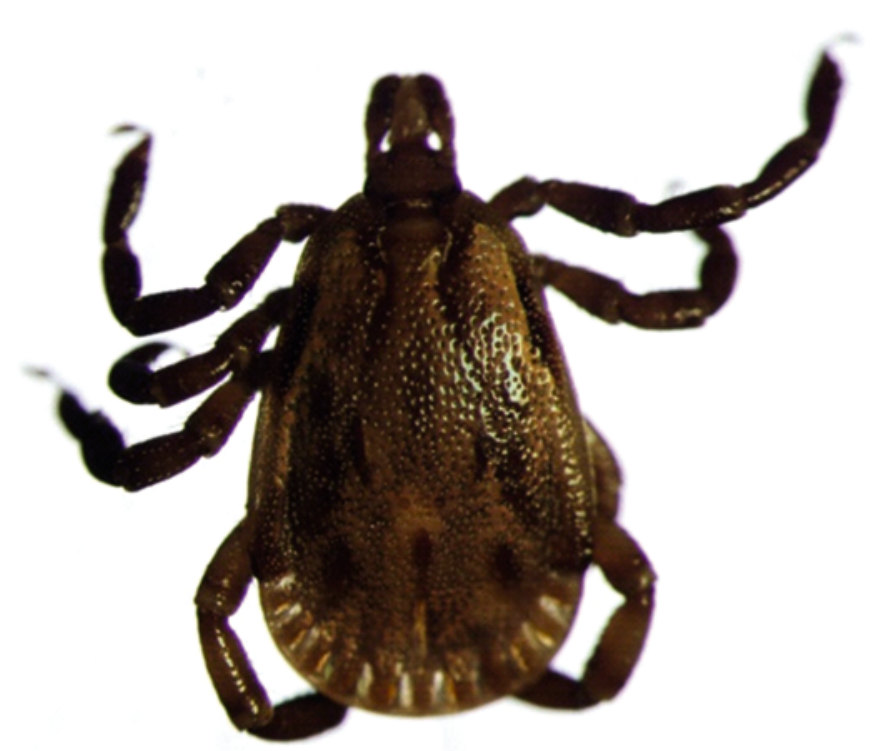

Figura 3 - Carrapato adulto macho da espécie A. aureolatum.

Fonte: Acervo do autor. 


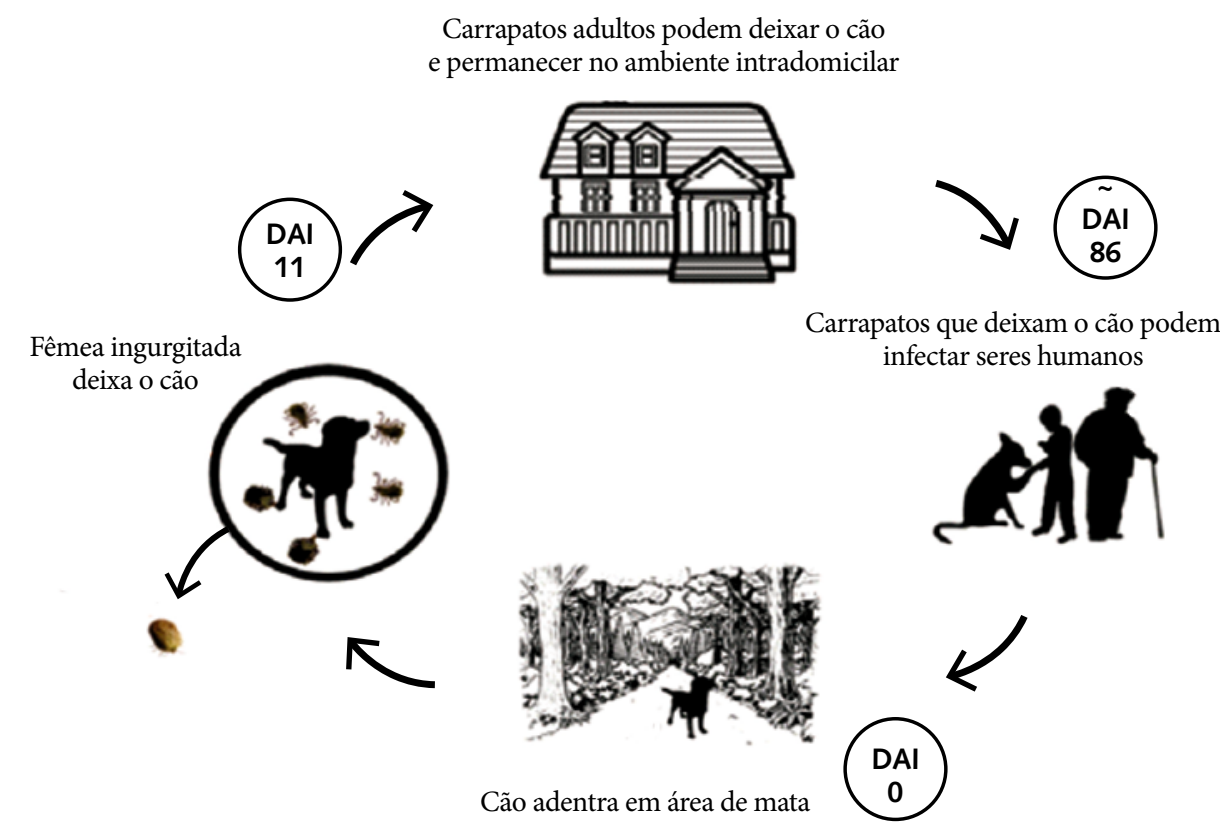

DAl: Dias após infestação

Figura 4 - Esquema representativo da forma de transmissão da FMB pelo $A$. aureolatum na RMSP. Fonte: PINTER et al., 2016.

O ciclo de vida do A. ovale (Figura 5) apresenta parasitismo por pequenos roedores silvestres nas fases imaturas e alta preferência por carnívoros na fase adulta. É o vetor de uma riquétsia pertencente ao grupo da febre maculosa, sendo denominada por Rickettsia parkeri - Estirpe Mata Atlântica, menos virulenta que a $R$. rickettsii.

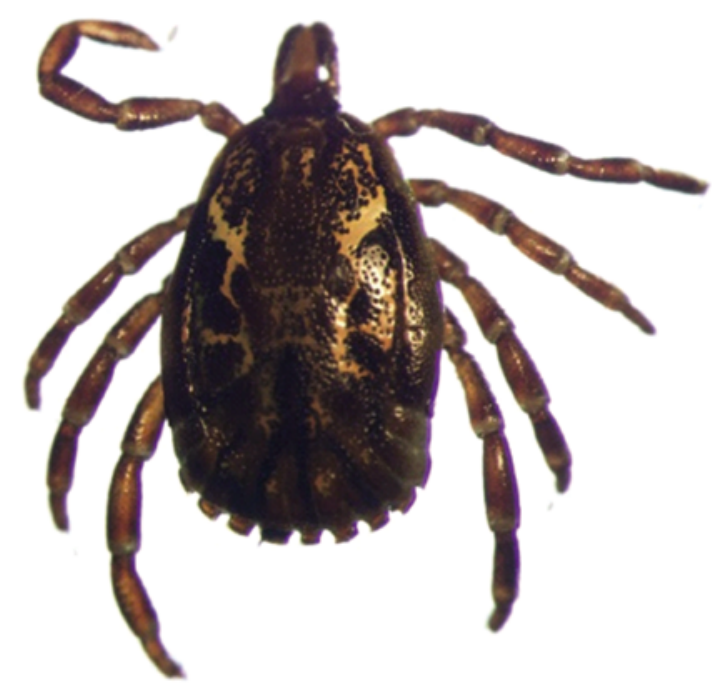

Figura 5 - Carrapato adulto macho da espécie A. ovale. Fonte: Acervo do autor.

Até o momento, não há registros de óbito pela $R$. parkeri. O ser humano é parasitado geralmente pela forma adulta do carrapato, e esse contato acontece normalmente de duas formas: a) cães domésticos que circulam em áreas de mata, levando o carrapato para as residências dos municípios litorâneos do estado; b) as pessoas que frequentam áreas de mata durante caminhadas em trilhas na floresta.

Observa-se que a transmissão de $R$. rickettsii não ocorre diretamente entre humanos, mas pela picada do carrapato durante o respasto sanguíneo, após um período mínimo de 10 minutos de parasitismo (SARAIVA et al., 2014).

Com menor possibilidade, a infecção de humanos pelas Rickettsia sp também pode acontecer quando da retirada incorreta de carrapatos parasitados com as mãos sem proteção, ou o esmagamento do artrópode com as unhas, penetrando a riquétsia, ou mucosas íntegras, na pele lesada. Há também relatos de transmissão da bactéria em acidentes de laboratório.

Entre os carrapatos, a infecção pelas riquétsias ocorre pelas vias transovariana (da fêmea para seus ovos), transestadial (das larvas até as fases de ninfa e adulta, permanecendo durante toda a vida), pela cópula e alimentação em um animal que esteja em período de bacteremia (riquetsemia). Para muitas espécies de riquétsia (ex. R. africae, R. rhipicephalus), o mecanismo de sobrevivência na população de carrapatos é tão eficiente que possivelmente garante, por si só, a manutenção de riquétsias na natureza. Para outras espécies, tal como $R$. rickettsii, esse mecanismo é menos eficiente, pois a infecção por essa espécie no carrapato pode diminuir a capacidade reprodutiva de fêmeas adultas, podendo ser inclusive letal para o ixodídeo (BURGDORFER, 1988). Neste caso, os animais vertebrados, hospedeiros naturais dos vetores da $R$. rickettsii, devem assumir um papel fundamental na amplificação da infecção da bactéria na 
população dos transmissores da doença. Diante dessa situação, desde o início do século XX, pesquisadores da América do Norte e do Sul tentam encontrar animais silvestres naturalmente infectados por $R$. rickettsii, a fim de compreender melhor a ecologia da febre maculosa.

Horta et al. (2009) avaliaram a infecção de gambás (Didelphis aurita) por Rickettsia rickettsii e seu papel como hospedeiros amplificadores para transmissão horizontal para carrapatos A. sculptum (antigamente denominados Amblyomma cajennense), demonstrando que a bactéria foi capaz de infectar gambás sem causar doença e desenvolver riquetsemia suficiente para infectar cobaias e carrapatos. Souza et al. (2009) avaliaram capivaras (Hydrochoerus hydrochaeris), após serem inoculadas via intravenosa com material biológico contaminado com Rickettsia rickettsii, com relação ao seu papel como hospedeiros amplificadores para transmissão horizontal para carrapatos A. sculptum, demonstrando que a bactéria foi capaz de infectar os animais sem causar doença e desenvolver riquetsemia muito mais eficiente e com maiores intervalos de duração se comparados aos resultados de Horta et al. (2009), sendo suficiente para causar infecção em cobaias e carrapatos.Ueno (2014) avaliou os equinos (Equus caballus) após inoculações via intravenosa de Rickettsia rickettsii, e a bactéria foi capaz de infecctá-los causando resposta imunológica, mas não causou a doença, não houve riquetsemia, e os carrapatos que se alimentaram nos equinos durante o período de pós-inoculação do agente etiológico não foram infectados pelas riquétsias. Todos os animais e seres humanos podem ser infectados pela riquétsia. A doença desenvolve uma imunidade sólida e duradoura nos indivíduos que se recuperam, prevenindo-os de novas infecções pela mesma bactéria. A imunidade adquirida é provavelmente mediada por resposta celular e não humoral. O período de incubação da doença é de 2 a 14 dias.

\section{Sinais clínicos}

Os primeiros sintomas de seres humanos acometidos pela FMB são febre, mialgia e cefaleia intensa. O exantema raramente aparece no primeiro dia, mas em $60 \%$ a $70 \%$ dos casos, entre o $3^{\circ}$ ao $5^{\circ}$ dia após o início da febre, inicia-se nos punhos e tornozelos, disseminando-se para todo o corpo, incluindo as regiões palmares e plantares. No entanto, em alguns pacientes não há essa manifestação, podendo dificultar e/ou retardar o diagnóstico e posterior tratamento, provocando maiores ocorrências de letalidade. Também se observa a presença de edema nas mãos e nos pés, sendo que em alguns casos o edema pode se apresentar de maneira generalizada.
A doença também causa sepse com comprometimento pulmonar, podendo ocasionar insuficiência respiratória aguda, problemas renais, como insuficiência renal aguda, diátese hemorrágica e lesões neurológicas com meningite, encefalite e icterícia. As sequelas, quando presentes, são neurológicas e/ou apresentam alterações vasculares importantes, podendo provocar quadros necróticos, principalmente em regiões de extremidades, que podem levar o acometido à necessidade de amputações e enxertos. Nos casos clínicos com diagnóstico e tratamento tardios, o óbito ocorre usualmente entre o $5^{\circ}$ e o $15^{\circ}$ dia após o início dos sintomas.

\section{Diagnóstico}

Em decorrência da inespecificidade das manifestações clínicas da FMB, muitas vezes seu diagnóstico é confundido com outras doenças infecciosas (como a dengue, zika, rubéola, sarampo, sífilis, meningite e leptospirose, entre outras) ou com reações medicamentosas e alérgicas, sendo a causa, muitas vezes, do retardo na obtenção do diagnóstico e início da terapia específica.Embora seja raro, há casos com sintomas gastrointestinais proeminentes que podem sugerir ao clínico suspeitar que a doença esteja relacionada com um quadro de gastroenterite aguda ou abdome agudo cirúrgico; nas situações mais graves, há presença de manifestações hemorrágicas e icterícia. A anamnese ocupa um papel essencial para delinear os fatores epidemiológicos e de risco, necessários para direcionar a suspeita diagnóstica.Em São Paulo, o Instituto Adolfo Lutz Central (IAL), é o laboratório de referência regional autorizado pelo Ministério da Saúde para a realização de exames específicos.

\section{Diagnóstico específico}

\section{Método indireto}

Reação de imunofluorescência indireta (RIFI): método sorológico no qual os anticorpos presentes na amostra de sangue do hospedeiro possivelmente infectado reagem com o antígeno (riquétsias), gerando um sinal de fluorescência nas amostras positivas. Recomenda-se que a coleta das amostras seja pareada (de 15 a 21 dias), sendo a primeira coleta na fase aguda da doença, período de início das manifestações clínicas (de 7 a 10 dias após se infestar pelo carrapato). Para considerar uma amostra positiva, é necessário visualizar soroconversão (elevação $\geq$ a 2 títulos ou 4 vezes a diluição da $1^{\text {a }}$ para a $2^{\text {a }}$ ) para produzir um resultado mais confiável, uma vez que associa a produção de anticorpos (infecção produtiva) com os sintomas clínicos compatíveis com a FM. 


\section{Método direto}

Reação em cadeia da polimerase (PCR): método que se apoia na replicação do material genético (DNA) da riquétsia. Os materiais examinados podem ser dos soros dos pacientes com suspeita de FMB realizados no Instituto Adolfo Lutz (IAL) da Secretaria de Saúde do Estado de São Paulo, e os carrapatos podem ser retirados dos doentes com suspeita de FMB, no Centro de Controle de Zoonoses (CCZ) da Prefeitura Municipal de São Paulo. Nas amostras positivas de carrapatos, o material é encaminhado ao Laboratório de Doenças Parasitárias da Faculdade de Medicina Veterinária e Zootecnia da Universidade de São Paulo (FMVZ-USP) para dar sequência ao tratamento.

Cultura com isolamento: método diagnóstico específico para identificar o agente etiológico que possibilita a diferenciação das riquétsias já identificadas ou não. Como a manipulação de riquétsias vivas representa um maior risco aos profissionais que executam a técnica laboratorial, deve-se apenas realizar essa metodologia em condições de segurança para classe de risco três. Portanto, o método deve ser realizado apenas em casos muito graves e específicos, em que os outros métodos disponíveis não possam obter os resultados necessários.

\section{Tratamento}

Após início das manifestações clínicas, o tratamento deve ser iniciado precocemente, sendo um fator determinante na diminuição da letalidade. Num tratamento precoce, a terapêutica revela-se bastante eficaz, com queda do quadro febril após 24 a 72 horas do início do tratamento. A administração do antibiótico poderá ser interrompida após dois ou três dias do desaparecimento da febre, e o tratamento iniciado após o $4^{\circ}$ dia do início dos sintomas pode não ter a eficácia esperada, ocasionando consequências graves. A doxiciclina é o antimicrobiano de escolha para os pacientes com suspeita de FMB, independente da idade. Em casos de infestação de carrapatos em humanos, sem apresentação das manifestações clínicas, não é recomendado o tratamento antibiótico profilático, independente da área de transmissão ou do risco para a doença, devendo-se orientar que o paciente observe o aparecimento de sintomas, como febre e quadros de cefaleia, dentro de um período de até 14 dias após a retirada do artrópode. Caso os sintomas estejam presentes, deve-se procurar o médico e informar sobre a exposição ao vetor da doença, sendo tal relato de suma importância para a suspeita de FMB.

\section{Medidas de vigilância e controle}

Deve-se divulgar a doença para a população (unidades de saúde, escolas, associações, centros comunitários, entre outros), repassando conhecimentos sobre sua existência, medidas preventivas e a importância do envio de carrapatos coletados nos pacientes ou encontrados no ambiente para sua identificação. A divulgação junto às equipes de saúde deve priorizar: a) a importância de questionar os antecedentes epidemiológicos do paciente para orientá-lo no diagnóstico e realizar um tratamento precoce; b) iniciar a antibioticoterapia logo após suspeitar da doença; c) a importância da coleta dos exames para confirmar o diagnóstico e da notificação para a realização de ações preventivas nas áreas de transmissão da doença; d) a observação do surgimento de sinais clínicos dentro do período de duas semanas, para os pacientes assintomáticos que foram parasitados por carrapatos.

A divulgação para a população deve enfatizar a importância de: a) evitar que cães e gatos circulem em áreas de mata; b) evitar contato próximo com animais que frequentam áreas de mata; c) dar destinação adequada ao lixo e restos alimentares para evitar que sejam atrativos para animais silvestres, ou sendo uma forma de alimentação para a permanência de populações de cães e gatos errantes; d) praticar a guarda responsável de cães e gatos; e) retirar carrapatos aderidos tanto em animais como em pessoas, com os devidos cuidados; f) observar o aparecimento de sintomas até duas semanas após ter tido contato com carrapatos, caso em que se deve procurar assistência médica e informá-la da ocorrência desse parasitismo prévio.

\section{Programas educativos}

O sucesso dos programas de controle e profilaxia da FMB assenta-se no emprego de boas estratégias educativas, com o emprego de ações bem planejadas e integrativas, adaptadas para diferentes tipos de público: profissionais da saúde, gestores e a população em geral. Essas ações permitirão a implementação dos programas de promoção da saúde, com destaque para a capacitação de indivíduos para a tomada de ações no caso de uma possível ocorrência da doença. As estratégias educativas diferem-se de acordo com a situação epidemiológica evidenciada em cada localidade. Os dados epidemiológicos da ocorrência da doença deverão nortear o planejamento das estratégias de intervenção de acordo com a relevância do problema em cada área e para o respectivo público envolvido. (*)

\section{Referências}

BURGDORFER, W. Ecological and epidemiological considerations of Rocky Mountain spotted fever and scrub typhus. In: WALKER, D. H. (Ed.). Biology of rickettsial diseases. Boca Raton: CRC, 1988. p. 33-50.

HORTA, M. C. et al. Experimental infection of opossums Didelphis aurita by Rickettsia rickettsii and evaluation of the transmission of the infection to ticks Amblyomma cajennense. Vector Borne and Zoonotic Diseases, Larchmont, v. 9, n. 1, p. 109-118, 2009. 
LABRUNA, M. B. et al. Experimental infection of Amblyomma aureolatum ticks with Rickettsia rickettsii. Emerging Infectious Diseases, Atlanta, v. 17, n. 5, p. 829-834, 2011.

MCKIEL, Y. A.; BELL, E. J.; LACKMAN, D. B. Rickettsia canada: a new member of the typhus group of rickettsiae isolated from Haemaphysalis leporispalustris ticks in Canada. Canadian Journal of Microbiology, Ottawa, v. 13, n. 5, p. 503-510, 1967.

PACHECO, R. C. et al. Rickettsia monteiroi sp. nov., infecting the tick Amblyomma incisum in Brazil. Applied and Environmental Microbiology, Washington DC, v. 77, n. 15, p. 5207-5211, 2011.

PAROLA, P.; PADDOCK, C. D.; RAOULT, D. Tick-borne rickettsioses around the world: emerging diseases challenging old concepts. Clinical Microbiology Reviews, Washington DC, v. 18, n. 4, p. 719-756, 2005.

PINTER, A. et al. Febre maculosa brasileira. BEPA, Boletim Epidemiológico Paulista, São Paulo, v. 8, n. 1, p. 3-31, 2011. Suplemento.
PINTER, A. et al. (Coord.). A febre maculosa brasileira na região metropolitana de São Paulo. BEPA, Boletim Epidemiológico Paulista, São Paulo, v. 13, n. 151, p. 3-47, 2016.

SARAIVA, D. G. et al. Feeding period required by Amblyomma aureolatum ticks for transmission of Rickettsia rickettsii to vertebrate hosts. Emerging Infectious Diseases, Atlanta, v. 20, n. 9, p. 1504-1510, 2014.

SOUZA, C. E. et al. Experimental infection of capybaras Hydrochoerus hydrochaeris by Rickettsia rickettsii and evaluation of the transmission of the infection to ticks Amblyomma cajennense. Veterinary Parasitology, Amsterdam, v. 161, n. 1-2, p. 116-121, 2009.

UENO, T. E. H. Infecção experimental de equinos por Rickettsia rickettsii e avaliação da transmissão para carrapatos Amblyomma cajennense. 2014. 84 p. Tese (Doutorado em Epidemiologia Experimental Aplicada às Zoonoses) - Faculdade de Medicina Veterinária e Zootecnia da Universidade de São Paulo, São Paulo, 2014. 